\title{
Innovations in postgraduate work integrated learning within the perioperative nursing environment: A Western Australian experience
}

Follow this and additional works at: https://www.journal.acorn.org.au/jpn

Part of the Health Services Administration Commons, Health Services Research Commons, Perioperative, Operating Room and Surgical Nursing Commons, and the Surgery Commons

(c) (i)

This work is licensed under a Creative Commons Attribution 4.0 License.

\section{Recommended Citation}

Russell, Kylie and Coventry, Tracey (2016) "Innovations in postgraduate work integrated learning within the perioperative nursing environment: A Western Australian experience," Journal of Perioperative Nursing: Vol. 29 : Iss. 4 , Article 1.

Available at: https://doi.org/10.26550/2209-1092.1007

https://www.journal.acorn.org.au/jpn/vol29/iss4/1

This Article is brought to you for free and open access by Journal of Perioperative Nursing. It has been accepted for inclusion in Journal of Perioperative Nursing by an authorized editor of Journal of Perioperative Nursing. 


\section{Authors \\ Dr Kylie Russell \\ PhD, MHlthSc(Ed), BN, ACN, ANZHPE, ANTS, STTI, ANF \\ Postgraduate Coordinator, School of Nursing \& Midwifery, The University of Notre Dame}

Tracey Coventry

MNEd, BSc (Nursing), ANTS, STTI, ANF Assistant Postgraduate Coordinator, School of Nursing \& Midwifery, The University of Notre Dame

\section{Corresponding author}

Dr Kylie Russell

PhD, MHlthSc(Ed), BN, ACN, ANZHPE, ANTS, STTI, ANF

Postgraduate Coordinator, School of Nursing \& Midwifery, The University of

Notre Dame

Kylie.russell@nd.edu.au

T: +61894330563

\title{
Innovations in postgraduate work integrated learning within the perioperative nursing environment: A Western Australian experience
}

\author{
Abstract \\ A key expectation from the health care industry in Australia is \\ that nurses engaged in postgraduate specialist education need \\ to be able to apply their extended knowledge and skills to the \\ workplace. For this to succeed, health services need to be involved \\ in the development of course content and learning outcomes \\ to ensure authentic engagement. Essential to this is student \\ participation in workplace learning that provides experience, \\ performance feedback and reflection. This promotes graduate \\ success to meet industry expectations.
}

The Graduate Diploma of

Perioperative Nursing aims to develop graduates with not only the knowledge of good perioperative nursing practice but also the skills. To achieve this, the course is provided in collaboration with both public and private health care sites within Western Australia $(n=12)$. The 12-month, clinically intensive course provides a combination of academic learning and assessment in conjunction with clinical rotations amounting to a minimum of 1,150 hours.

A variety of evaluations have demonstrated the positive impact of the course. These include the university teaching and unit content evaluations; the Course Experience Questionnaire (CEQ), administered by Graduate Careers Australia; and the independent School of Nursing and Midwifery Course Review.

These evaluations indicate that the perioperative course is well received by health services, educators and students. Further research to confirm these results is required to validate the impact of the course on nursing performance, retention and the value of work integrated learning within postgraduate nursing education.

\section{Key words}

Work integrated learning, perioperative nursing, postgraduate education

\section{Introduction}

The perioperative setting is a complex and challenging environment. Registered nurses new to working in the area encounter a number of role changes from the traditional, wardbased clinical practitioner. With fewer undergraduate programs providing perioperative learning experiences, the operating room is often a place that nurses must simply commit to and learn about with little background preparation. In acknowledgement of this, a large teaching hospital in Western Australia introduced a Certificate 
of Perioperative Nursing in 2001. In 2007, it was revitalised and accredited through the University of Notre Dame, Australia. That course, now the Graduate Diploma of Perioperative Nursing, has continued to evolve to meet the demands of the perioperative environment and the need for academic integrity.

This project is being carried out in two phases. Phase 1 consists of a review of the Graduate Diploma of Perioperative Nursing and compares the course to associated courses in Australia. Phase 2 will be a formal evaluation involving a mixed method approach to determine the impact of the perioperative course on student outcomes. This paper will provide an outline of Phase 1 including an overview of the Australian perioperative learning environment, a summary of the principles of workbased learning, an evaluation of the Graduate Diploma of Perioperative Nursing and an outline of Phase 2 of the project, a formal research evaluation.

\section{Background and significance}

Prior to 2001, Fremantle Hospital and Health Service struggled to recruit perioperative nurses. Undergraduate placements in the perioperative environment in Australia were limited and, while no formal report acknowledges this, a review of Australian curricula for nursing registration available on the web also confirms this as the current state. According to one of the hospital's course coordinators, this lack of experience within the specialty was thought to have influenced recruitment so Fremantle Hospital and Health Service introduced a perioperative nursing course to provide a comprehensive learning environment for registered nurses to consolidate their knowledge and skill set in this specialised practice area. The course was designed for nurses with little or no perioperative experience and focused on providing a supportive transition to the perioperative environment.

As applications to do the course increased, places were increased and a work integrated learning approach was adopted that included both the public and private health care sector across tertiary and secondary centres. The course became accredited through the University of Notre Dame and a partnership was formed between the university and twelve Western Australian health care sites with each site hosting between one and four students.

\section{Perioperative courses in Australia}

Through accessing various university websites, a review of available perioperative courses in Australia found eleven courses that provide a university qualification: six at the graduate certificate level, three at graduate diploma and two at master's. A number of different modalities of course delivery are available. Two courses provide advanced standing to health service perioperative courses, with students required to complete further general professional development units at the university to achieve a graduate certificate. Four courses (two certificate and two diploma) provide online units whereby students are required to have employment within the perioperative environment to obtain clinical learning but there is no formal relationship between the hospital and the university. If employment is not available, students can request a supernumerary placement to meet the course's clinical hours requirements. Three courses (one at each (evel) provide online learning with no requirement for employment or clinical placement. The Notre Dame course seems to be unique in its partnership approach, providing students with direct enrolment with the university as well as employment with selected health care services where university lecturers are onsite and responsible for clinical teaching and assessment.

\section{Work integrated learning}

The term 'work integrated learning' describes the collaboration between higher education institutions and industry to provide workplace learning. Workplace learning supports the application of theory to practice which develops the essential skills, experience and an understanding of the 'real' world of the chosen profession ${ }^{1,2}$. For the purpose of this paper, the term is used in the perioperative nursing context to describe the intersection of the Graduate Diploma of Perioperative Nursing curriculum with the health services' perioperative specialty. New and experienced perioperative nurses are able to participate in formal academic learning in the clinical environment. A variety of learning and teaching strategies are incorporated through the collaboration of the health care services' perioperative nurse educators and the university's course coordinator. Postgraduate work integrated learning invests in quality and safe patient outcomes through the clinical, professional and academic capacity for the practice of perioperative nurses.

\section{Bridging academic and clinical learning}

The Notre Dame Academic Council approved the perioperative course in 2006, with all course and unit requirements meeting the award of graduate diploma. These university requirements, linked to the Australian Qualifications Framework $(A Q F)^{3}$, ensure academic integrity. This involved the development of 
learning outcomes, for the whole course and individual units, through stakeholder engagement with specialist perioperative nurses. Academic integrity was further maintained through a review of the existing teaching content, articulated in each unit outline, with appropriate assessment criteria at the graduate diploma level, including criteria for clinical assessment. The Graduate Diploma of Perioperative Nursing maps into the Master of Nursing by coursework. This provides a direct pathway into further study at the master's level.

To ensure ongoing stakeholder engagement, each participating health care site has a nominated 'clinical site lead' who is assigned an Adjunct Lecturer position with Notre Dame. This ensures course quality through appropriately allocated nurse educators that meet the AQF standard for education ${ }^{3}$. These clinical leads, in addition to the university's course coordinator and Postgraduate Coordinator form the 'Management Committee'. The Management Committee meets twice a year for review and mapping of course content, teaching and assessment moderation, and professional development in relation to academia. This safeguards the contemporary nature of the course and meets the needs of all parties. The Graduate Diploma of Perioperative Nursing Course Coordinator maps teaching content and assessment to each unit and course outline.

The course commences in February each year and runs for a period of 12 months. Health care services recruit students from external and internal sources, according to available staffing positions, with assistance from the university course coordinator. Students, who are then employed with the health care service for the duration of the course, work a minimum of 32 hours per week. University fees are significantly reduced due to the integrated nature of the course because the health service clinical site leads (who are paid by the health service to be adjunct lecturers) provide the face-to-face teaching and assist with marking of student assessments. This significantly reduces the university's staffing costs and this cost saving is reflected in reduced unit fees charged by the university.

Six academic units engage students in examination and analysis of professional, ethical, evidencebased and reflective practice in conjunction with studying the principles of education, management and leadership. A variety of assessment techniques are used, including clinical and written tasks and individual and group work. The variety of assessment tasks provides the opportunity to evaluate students' understanding and application of the numerous principles that ensure good patient outcomes in the perioperative environment.

Students rotate between specialty areas to gain generic and specialist skills in the perioperative environment that will assist them with their chosen career path. Whilst rotations between health care sites are not compulsory, hospitals are encouraged to support 'student swaps' to allow a broader understanding of the perioperative environment. Students' clinical ability is assessed through the Clinical Assessment Tool (CAT) based on the Australian College of Perioperative Nurses (ACORN) Standards for Perioperative Nursing in Australia ${ }^{4}$. These standards outline the specialty knowledge and skills of perioperative nurses.

Clinical learning through allocated shifts with mentors is consolidated through face-to-face study days and online learning. The course commences with a week-long, intensive orientation program followed by a further five study days across the 12 months. Face-toface learning involves a mixture of learning modalities including lectures, simulation, role-play and problembased learning. In addition, students have access to online learning material through the university's Blackboard Learnit system. Each health care site hosts an orientation day or study day thereby sharing the teaching load and providing access to health professionals with specialty knowledge across the sites.

Assessment moderation across sites and specialty areas of practice is achieved through peer and academic review. Double marking by the clinical site lead and the university course coordinator ensures consistency and quality. In addition, each clinical site lead marks essays by students from different health care sites. This moderation of assessments ensures both a clinical specialist and an academic provide feedback for each paper, and moderation across the sites confirms fair grade distribution.

\section{Evaluating the Graduate Diploma of Perioperative Nursing}

Evaluations of the Graduate Diploma of Perioperative Nursing, using a number of methods, continue to highlight the success of the course from both the student and industry perspectives. These evaluations occur within each participating health service, as well as the university, and results are compared to national data. 


\section{Evaluation methods}

Each health service provides students with the opportunity to complete a study day and course evaluation. These are compiled through the year and shared with the group, allowing the Management Committee to consider changes for future study day programming. Individual health care sites also use these evaluations to meet their own accreditation and training reporting requirements. The evaluations used by the university include the Notre Dame teaching performance and unit content evaluations, completed at the end of each unit of study, with the results analysed by the University Quality Management Office. The Course Success Rate narrates the successful completion of the course by the student cohort and is indicated by the percentage of students achieving a pass mark as well as overall course retention. The school and course reviews by the School of Nursing and Midwifery are an external independent review of a school and its courses by industry representatives and external academics. This process is completed each four years and consists of a two-day onsite visit and comprehensive report.

On finishing the course, students are invited to complete the Course Experience Questionnaire (CEQ). The CEQ is implemented by Graduate Careers Australia and gathers information from students about their perception of the course teaching and learning environment. Questions relate to the course content in developing skills, the teaching quality of the course, support practices and overall course satisfaction. Course reports are collated and compared with the national data.

\section{Evaluation findings}

Findings from each of these data sources continue to support the Graduate Diploma of Perioperative Nursing in its current format. A number of changes to the course have been implemented throughout its long history and, in many cases, they have been in response to these data sets. This confirms the robustness of this ongoing evaluation and the commitment of the Management Committee to reviewing feedback and responding appropriately.

Student feedback about health service study days and the overall course content has remained positive. Comments from the 2015 group include:

I would like to say that the course was fantastic; the study days were beneficial especially the one on orthopaedics as it answered all my queries and I am much more confident in orthopaedic surgeries now that I know how to use the instruments. (2015 participant 1)

I think the Graduate Diploma [of Perioperative Nursing] is a very intensive course that would be impossible to complete without continuous clinical exposure. Theatre is an area of nursing that is very different to all others and there is such a huge volume of knowledge that needs to be imparted to the novice theatre nurse that clinical experience is essential. Being exposed to numerous specialties within the theatre environment with the aid of clinical rotations was an added bonus. The postgraduate year was a very rewarding educational experience. (2015 participant 7)

The university evaluation for the unit content and teaching in all units has consistently achieved 'agree' or 'strongly agree' outcomes with the mean average well above the university minimum standard. In 2014 the overall satisfaction for each unit of study was an average of 95.3 per cent. The University Course Success Rate (2012-2014), as indicated by a pass mark, remains significantly high (90-100 per cent), with no fails and only one student withdrawing from the 2013 course and one from the 2014 course. The School of Nursing and Midwifery 2014 School Review panel commended the consistently high quality of course material provided by the Notre Dame course coordinator and health service site leads. In particular, the incorporation of relevant and contemporary professional issues into reflective and evidence-based practice assignments was commended, highlighting the school's positive and innovative approach to integrating clinical learning with academia to develop the nursing profession.

The CEQ data indicated that, for all areas of the survey, student responses were similar to or higher than the national average. The overall course satisfaction, as defined by Graduate Careers Australia, was 94 per cent, compared to the national average of 82 per cent for similar postgraduate courses. The data indicated that students described the structure and content of the course as highly relevant to both new and experienced perioperative nurses.

\section{Discussion - Phase two}

The Graduate Diploma of Perioperative Nursing provides a unique educational experience for perioperative registered nurses. The nature of the course, linking industry with academia, has demonstrated successful educational outcomes and ensures students are assessed on their clinical, professional and academic abilities ${ }^{5}$. 
Within nursing education and industry there has been, and still is, ongoing discussion and concern about the practice-theory gap in undergraduate and other entry to practice courses ${ }^{6}$. These same concerns translate to the postgraduate environment where courses with a clinical association cannot validate clinical and professional competence in their learning outcomes without student engagement in the clinical environment. The opportunity for supernumerary postgraduate clinical placements outside of an employment contract has been limited. In addition, loss of income and the expense of course fees reduce participant interest in and ability to commit to study.

The Graduate Diploma of Perioperative Nursing provides an innovative model that can deliver the successful integration of clinical, professional and academic learning and assessment. Evaluations from the students and feedback from participating health care sites indicate that this unique work integrated learning approach is meeting the varied expectations of all involved.

In the second phase of the project, the authors intend to undertake further research to determine the impact of the course on participant knowledge and skills from the perspective of the students and their line managers, the retention rate of students within the perioperative area and nursing, and the academic support provided to clinical site leads in their role within the health service.

\section{Recommendations}

The Graduate Diploma of Perioperative Nursing aims to provide a work integrated learning environment for students that supports both clinical and academic success. The collaboration between the university and health care sector provides a unique combination of expertise to achieve this aim. The impact of this approach on successful student outcomes has been overwhelmingly demonstrated through the various evaluation methods outlined in this article. Universities and health care services working together to achieve positive learning outcomes in the practicebased profession of nursing must be encouraged. A formal course evaluation involving students and industry and using a mixed method framework will occur late in 2016.

\section{Conclusion}

The Graduate Diploma of Perioperative Nursing offers a competitive edge to new and experienced registered nurses in the perioperative environment. The course provides consistent, collaborative and contemporary learning opportunities for advancing current practice and contributing to the contemporary perioperative specialty. Prospects for registered nurses to study within this specialty area of practice are essential for the development of an educated workforce.

\section{Acknowledgement}

The authors would like to acknowledge the Fremantle Hospital and Health Service nursing management, education department and executive whose vision and leadership supported the introduction of the perioperative course and its accreditation with the University of Notre Dame. Ongoing success of the course would not have been possible without the participating health care services that continue to provide specialist staff and placements for students. The dedication of the perioperative nurse educators and mentors has also been integral to the success of the course and its students.

\section{References}

1. Drysdale MTB, McBeath ML, Johansson K, Dressler S, Zaitseva E. Psychological attributes and work-integrated learning: An international study. Higher Education, Skills and Work-Based Learning 2016;6(1):20-34.

2. Johnston M, Bishop R. Noongar Dandjoo: A work integrated learning case study. Asia Pacific Media Educator 2012;22(2):165-177.

3. Australian Qualifications Framework South Australia [Internet]. Australian Qualifications Framework Council 2013 [cited 2016 Apr 23]. Available from: www.aqf.edu.au/.

4. Australian College of Operating Room Nurses Ltd. Standards for Perioperative Nursing in Australia $14^{\text {th }}$ Ed. Adelaide, South Australia: ACORN; 2016.

5. Lyckhage ED, Pennbrant S. Work-integrated learning: A didactic tool to develop praxis in nurse education. Adv Nurs Sci 2014;37(1):61-69.

6. Romyn DM, Linton N, Giblin C, Hendrickson $B$, Limacher LH, Murray C, et al. Successful transition of the new graduate nurse. Int J Nurs Ed Scholarsh 2009;6:Article 34.

Seeking manuscript reviewers
If you are a perioperative nurse from an academic, educational, managerial or
clinical background you could join ACORN's manuscript review team.
For more information visit our website at www.acorn.org.au/journal/ review-a-
AUSTRALIAN COLLGE OF
manuscript.
If you would like to join our team of manuscript reviewers, please contact the
ACORN Journal Editor on journaleditor@acorn.org.au or the ACORN office.

